\title{
Prevalence and associated factors of sexual violence among private college female students in Bahir Dar city, North Western Ethiopia ${ }^{*}$
}

\author{
Bizuayhu Shimekaw ${ }^{1 \#}$, Berihun Megabiaw ${ }^{2}$, Zelalem Alamrew $^{3}$ \\ ${ }^{1}$ Department of Public health, Faculty of Health Sciences, Andenet Medical College, Dangila, Ethiopia; \\ \#Corresponding Author: fbizuayhu@gmail.com \\ ${ }^{2}$ Department of Epidemiology and Biostatistics, School of Public Health, College of Medicine and Health Sciences, University of \\ Gondar, Gondar, Ethiopia; beredomega@gmail.com \\ ${ }^{3}$ Department of Public Health, College of Medicine and Health Sciences, Bahir Dar University, Bahir Dar, Ethiopia; \\ kzolam@gmail.com
}

Received 1 April 2013; revised 1 May 2013; accepted 11 June 2013

Copyright (c) 2013 Bizuayhu Shimekaw et al. This is an open access article distributed under the Creative Commons Attribution License, which permits unrestricted use, distribution, and reproduction in any medium, provided the original work is properly cited.

\section{ABSTRACT}

Background: Despite the higher risk victimization of young women in Ethiopia, the prevalence of sexual violence and its determinants among college students were scarce, particularly in the study area. This study was undertaken to determine the prevalence and associated factors of sexual violence among female private college students in Bahir Dar city. Methods: A cross sectional study was conducted in April 2012 among $\mathbf{5 4 1}$ female college students in Bahir Dar city using multistage sampling technique. A pretested self-administered questionnaire was used. The data were analyzed in bivariate and multivariate logistic regression analysis with SPSS version 16 soft ware package. Result: The study revealed that the prevalence of sexual violence among female college students was $37.3 \%$. Respondents whose childhood background from rural areas were more than four times likely to have had sexual violence $(A O R=4.51,95 \% \mathrm{Cl}$ : 1.67 - 12.16). The odds of sexual violence were higher for those respondents who had a close friend who drank alcohol $(A O R=3.13,95 \% \mathrm{Cl}$ : 1.09 - 8.97). Besides, respondents who had never discussed on reproductive health issues with their parents were more than four times

*Competing interests: The authors declare that they have no competing interests.

Authors' contributions: BS wrote the proposal, analyzed the data and drafted the paper. BM and ZA took part in proposal development, participated in data analysis and revised subsequent drafts of the paper. All authors read and approved the final manuscript. likely to have had sexual violence $(A O R=4.36$, 95\% Cl: 1.40 - 13.56). Conclusion: This study shows that sexual violence among female college students is higher. Sexual violence is associated with certain variables such as rural childhood residence, having a close friend who drank alcohol, and not discussing reproductive issues with parents. Therefore, it is recommended that sexual violence needs due attention and remedial action from policy makers, college officials, parents, students and other concerned bodies.

Keywords: Sexual Violence; Female College Students; Bahir Dar City; and Ethiopia

\section{BACKGROUND}

According to the United Nations Declaration, violence against women includes any act of gender based violence that results in physical, sexual, psychological harm or suffering to women, including threats or such acts, as durable deprivation of liberty, whether occurring in public or private life [1].

In developing countries information tended to focus on problems indicating of women's health status has seen relatively scarce. For the health of women, it is important to focus on the safe motherhood initiative and to meet the full range of women's reproductive health needs. Sexual violence is the main component of overall violence against women; due to fear of universal stigma, evidence is still limited [2].

According to multi-country WHO study, it was found 
that $0.3 \%$ to $12 \%$ of women respondents reported being forced to have sex or to perform a sexual act that they did not want to by non-partners since the age of 15 years. The highest levels from $10 \%$ to $12 \%$ were reported in Peru, Samoa, and the United Republic of Tanzania city. The highest level of non-partner physical violence was reported in Samoa (62\%) with the next highest being in Peru $28 \%$ and $32 \%$ in the city and province, respectively [3].

A study conducted among high school students in Addis Ababa and Western Showa indicated that the prevalence of performed rape and attempted rape was 5\% and $10 \%$ respectively, and harassments was 74.3\% [4]. Another high school based prevalence study among female students in Debark, northwest Ethiopia reported the prevalence of performed and attempted rape as $8.8 \%$ and $11.5 \%$ respectively [5].

In Ethiopia, like any other third world countries, scientifically documented information regarding gender based violence is scarce. In general, evidences related to sexual violence in our country especially in college settings are scarce. To the best of our knowledge, studies related to sexual violence had not been conducted in the study area. Based on this understanding, it is important to investigate and document the prevalence and associated factors of sexual violence.

\section{METHODS}

\subsection{Study Setting}

Cross sectional study was conducted among female private college students in Bahir Dar town. Bahir Dar town which is a capital city of Amhara Regional state, located in Northwest part of the country and it is $565 \mathrm{~km}$ far from Addis Ababa, capital city of Ethiopia.

\subsection{Participants}

The study participants were all female private college students registered for the academic year 2012 in all of the colleges found in the study area. A total of 541 private college female students were involved in the study. Multistage stratified sampling was employed considering all private colleges in Bahir Dar town, departments and year of study in the sampling process for the selection of the study subjects. The study was excluded blind female students for a reason that they couldn't read and complete the self administered questionnaire and extension students.

\subsection{Measurements}

The dependent variable was "sexual violence" (it includes rape and harassment in their life time). The independent variable includes Socio-demographic character- istics like age, marital status, religion, residence, department and year of educational level; Family background like Educational status of parents, living condition, family income; Sexual history like sexual activity, age at first sex, with whom doing first sex and number of sexual partner; Substance use such as drinking alcohol, chewing chat, smoking.

\subsection{Data Collection}

Data were collected using self-administered structured questionnaire. The questionnaire was adopted from reviewed literatures [6-8], translated to local language Amharic. Pre-test was done on 27 female students that were not included in the main survey and necessary changes were done to our questionnaire. Four supervisors were recruited to facilitate the data collection process. They were trained how to facilitate the data collection and contents of the questionnaire.

\subsection{Data Analysis}

Data was entered and analysed by SPSS V. 16. Bivariate analysis were carried out to see the association of each independent variable on the dependent variables and those who had less than 0.2 level of significance were remain in to the final models. Finally, stepwise multiple logistic regression analysis technique was carried out and p value of less than 0.05 was used as a cut off point for declaring the presence of association. Odds ratios and 95\% confidence intervals were also computed.

\subsection{Ethical Considerations}

Before starting of the data collection process, ethical clearance was obtained from the department of public health, Bahir Dar University. Written consent to participate in the study was secured, while providing the self administered questionnaire. For this a one page consent letter was attached to the cover page of each questionnaire stating about the general purpose of the study, issues of confidentiality and consent of the study participant. Participants' confidentiality of information was keep by excluding names as identification in the questionnaire.

\section{RESULTS}

\subsection{Socio-Demographic Characteristics of Study Subjects}

From a total of 541 study participants required, 536 female students were involved in the study, which makes good response rate (99.1\%). Of them 171 (31.9\%), 160 (29.9\%) and $205(38.2 \%)$ were $1^{\text {st }}$ year, $2^{\text {nd }}$ year and $3^{\text {rd }}$ year students, respectively. The mean age and standard 
deviation of the respondents were $20.3 \pm 1.8$ years and more than $96.8 \%$ were below the age of 24 years. Majority 487 (90.9\%) were orthodox Christians and 328 $(61.2 \%)$ of the respondents reported that grow in urban areas. Concerning the marital status of the respondents, $78(14.6 \%)$ of them were married, 141 (26.3\%) of them had boyfriend and the rest 317 (59.1\%) of them were not married or had no boyfriend. Current living condition of the respondents were reported 151 (28.2\%) of the respondents were living alone, 241 (45\%) were live with parents, 46 (8.6\%) were live with husband/boyfriend, 59 $(11.0 \%)$ and 39 (7.3\%) of students were live with female friends and relatives respectively (Table 1).

\subsection{Socio-Economic Status of Parents}

The majority of students (96.3\%) reported that they had support from their families if they face problem. About $79.3 \%$ of students reported that they received enough money according to their demand for education and other expenses whereas $20.7 \%$ of students did not receive enough money according to their demand for education and other expenses. The mean family monthly income of respondents was $3050.0 \pm 1928.1$ with a range 500 to 15,000 birr. Nearly $40 \%$ of students family had monthly income less than or equal to 2000 birr. Majority of respondents were receiving money on a monthly basis 266 (49.6\%), 33 (6.2\%) were receiving on a semester, 6 (1.1\%) were supporters send money once in a year, whereas 224 (41.8\%) respondents were families live in the vicinity and $7(1.3 \%)$ students were no money send at all. Family controlling status over students behavior were reported to be loose or free in 50 (9.3\%) of study participants (Table 2).

\subsection{Substance Use of Students}

Chewing chat, smoking cigarette/tobacco and drinking alcohol some day in their life was reported by 70 (13.1\%), 15 (2.8\%) and 173 (32.3\%) of the respondents respectively. Thirty nine (22.5\%) and 30 (17.3\%) of respondents reported that they were drunken since joining of the college and drunken in this academic year respecttively. Forty one (23.7\%) of the respondents reported that they had either male or female friends who drunken currently (Table 3).

\subsection{Sexual Experience}

From the total respondents 246 (45.9\%) reported that they had sexual experience. Majority of respondents (96\%) were started sexual intercourse before the age of twenty one years old. The mean age and SD for having the first sexual intercourse was found to be $18.6 \pm 1.6$ year. Sixty three (25.6\%) of the sexually active respon-
Table 1. Socio-demographic characteristics of study participants, in Bahir Dar town, Amhara region, North West Ethiopia, April 2012.

\begin{tabular}{|c|c|c|}
\hline Characteristics & Frequency & Percent (\%) \\
\hline \multicolumn{3}{|l|}{ Department } \\
\hline Secretary & 104 & 19.4 \\
\hline Accounting & 55 & 10.3 \\
\hline IT & 138 & 25.7 \\
\hline Nursing & 207 & 38.6 \\
\hline Pharmacy & 15 & 2.8 \\
\hline Land administration & 17 & 3.2 \\
\hline \multicolumn{3}{|l|}{ Age } \\
\hline$<20$ & 182 & 33.9 \\
\hline $20-24$ & 337 & 62.9 \\
\hline$\geq 25$ & 17 & 3.2 \\
\hline \multicolumn{3}{|l|}{ Religion } \\
\hline Orthodox & 487 & 90.9 \\
\hline Muslim & 39 & 7.3 \\
\hline Protestant & 8 & 1.5 \\
\hline Other & 2 & 0.4 \\
\hline \multicolumn{3}{|l|}{ Child hood residence } \\
\hline Urban & 328 & 61.2 \\
\hline Rural & 208 & 38.8 \\
\hline $\begin{array}{l}\text { Educational status of } \\
\text { husband/boyfriend }\end{array}$ & $\mathrm{n}=219$ & \\
\hline Illiterate & 3 & 1.4 \\
\hline 1 - 4 grade & 1 & 0.5 \\
\hline 5 - 8 grade & 4 & 1.8 \\
\hline 9 - 12 grade & 20 & 9.1 \\
\hline Above 12 grade & 185 & 84.5 \\
\hline I didn't know & 6 & 2.7 \\
\hline $\begin{array}{l}\text { Occupational status of } \\
\text { husband/boyfriend }\end{array}$ & $n=219$ & \\
\hline Student & 62 & 28.3 \\
\hline Teacher & 33 & 15 \\
\hline Employed & 116 & 53 \\
\hline Unemployed & 8 & 3.7 \\
\hline \multicolumn{3}{|l|}{$\begin{array}{l}\text { Current living condition of } \\
\text { respondents }\end{array}$} \\
\hline Living alone & 151 & 28.2 \\
\hline With parents & 241 & 45 \\
\hline With husband/boyfriend & 46 & 8.6 \\
\hline With female friends & 59 & 11 \\
\hline With relatives & 39 & 7.3 \\
\hline
\end{tabular}


Table 2. Socio-economic status of parent's of study participants, in Bahir Dar town, Amhara region, North West Ethiopia, April 2012.

\begin{tabular}{|c|c|c|}
\hline Characteristics & Frequency & Percent \%) \\
\hline \multicolumn{3}{|l|}{ Parents living condition } \\
\hline Living together & 397 & 74.1 \\
\hline Divorced/separated & 28 & 5.2 \\
\hline Only mother alive & 64 & 11.9 \\
\hline Only father alive & 20 & 3.8 \\
\hline Both of them not alive & 27 & 5 \\
\hline \multicolumn{3}{|c|}{ Educational status of father } \\
\hline Illiterate & 155 & 28.9 \\
\hline 1 - 4 grade & 102 & 19.0 \\
\hline 5 - 8 grade & 93 & 17.4 \\
\hline 9 - 12 grade & 49 & 9.1 \\
\hline Above 12 & 119 & 22.2 \\
\hline I don't know & 18 & 3.4 \\
\hline \multicolumn{3}{|c|}{ Educational status of mother } \\
\hline Illiterate & 245 & 45.7 \\
\hline 1 - 4 grade & 107 & 20.0 \\
\hline 5 - 8 grade & 71 & 13.2 \\
\hline 9 - 12 grade & 45 & 8.4 \\
\hline Above 12 & 62 & 11.6 \\
\hline I don't know & 6 & 1.1 \\
\hline \multicolumn{3}{|l|}{ Family monthly income } \\
\hline$\leq 2000$ & 212 & 39.8 \\
\hline $2000-4000$ & 175 & 32.8 \\
\hline$\geq 4000$ & 146 & 27.4 \\
\hline \multicolumn{3}{|l|}{ Who Support for learning } \\
\hline Parents & 344 & 64.2 \\
\hline Siblings & 116 & 21.6 \\
\hline Relatives & 11 & 2.1 \\
\hline Husband & 51 & 9.5 \\
\hline Boyfriend & 7 & 1.3 \\
\hline Other & 7 & 1.3 \\
\hline \multicolumn{3}{|l|}{ Amount of money received } \\
\hline$<550$ & 257 & 48.3 \\
\hline $550-1000$ & 190 & 35.7 \\
\hline$\geq 1000$ & 85 & 16 \\
\hline \multicolumn{3}{|l|}{ Family control } \\
\hline Tight & 282 & 52.6 \\
\hline Average & 204 & 38.1 \\
\hline Loose/free & 50 & 9.3 \\
\hline
\end{tabular}

Table 3. History of substance use of college female students in Bahir Dar city, North West Ethiopia, April 2012.

\begin{tabular}{ccc}
\hline Characteristics & Frequency & Percent (\%) \\
\hline Chat chewing frequency & $\mathrm{n}=70$ & \\
Every day & 2 & 2.9 \\
Once/twice a week & 18 & 25.7 \\
1 - 3 in a month & 24 & 34.3 \\
Occasionally, <once a month & 26 & 37.1 \\
Alcohol drinking frequency & $\mathrm{n}=173$ & \\
Every day & 1 & 0.6 \\
One/two times a week & 30 & 17.3 \\
1 - 3 in a month & 37 & 21.4 \\
Occasionally, <once a month & 105 & 60.7 \\
Had drink since joining & $\mathrm{n}=173$ & \\
the college & 39 & 22.5 \\
Yes & 134 & 77.5 \\
No & $\mathrm{n}=173$ & \\
Had drink in this \\
academic year \\
Yes
\end{tabular}

dents reported that they had experienced more than one sexual partner in their life time (Table 4).

From the total of 246 respondents who reported that they are sexually active, 70 (28.5\%) initiated sexual intercourse due to engagement in marriage, 63 (25.6\%) due to peer influence, 50 (20.3\%) initiated sex due to self desire, 20 (8.1\%) started for economic support, 15 (6.1\%) due to drunken, 10 (4\%) initiated sex to pass exam/for mark, 9 (3.7\%) due to false promise made, 6 (2.4\%) being forced to have sex and 3 (1.2\%) did for other reasons.

\section{Sexual Violence}

Among the total respondents, 37.3\% (95\%CI: 33.2\% $41.4 \%)$ reported any form of sexual violence. Sexual harassment was reported, 35.8\% (95\%CI: 31.7\% - 39.9 $\%)$ and $6.3 \%$ (95\%CI: $4.2 \%-8.4 \%$ ) reported forceful sexual intercourse (rape) in their life time. Rape cases were not reported for their family or police. Different reasons were listed for not telling about the condition to anybody for family or reporting to legal body.

From the total of respondents 192 students who have experienced sexual harassment, perpetrators were re- 
Table 4. Sexual experiences of private college female students in Bahir Dar town, Amhara region, North West Ethiopia, April 2012.

\begin{tabular}{|c|c|c|}
\hline Characteristic & Frequency(N) & Percent (\%) \\
\hline \multicolumn{3}{|l|}{ Started sexual intercourse } \\
\hline Yes & 246 & 45.9 \\
\hline No & 290 & 54.1 \\
\hline Age at first sexual intercourse & $\mathrm{n}=246$ & \\
\hline$<19$ years & 119 & 48.4 \\
\hline 19 - 21 years & 117 & 47.6 \\
\hline 22 years & 10 & 4 \\
\hline With whom doing first sex & $\mathrm{n}=246$ & \\
\hline Boy friend & 104 & 42.3 \\
\hline Husband & 67 & 27.2 \\
\hline Teacher & 3 & 1.2 \\
\hline Student & 40 & 16.3 \\
\hline Strange & 16 & 6.5 \\
\hline Neighbour & 15 & 6 \\
\hline Other & 1 & 0.5 \\
\hline Number of sexual partner in life & $\mathrm{n}=246$ & \\
\hline One & 177 & 72 \\
\hline Two & 43 & 17.5 \\
\hline Three & 22 & 8.9 \\
\hline Four \& above & 4 & 1.6 \\
\hline \multicolumn{3}{|l|}{$\begin{array}{l}\text { Discussing reproductive health } \\
\text { with parents }\end{array}$} \\
\hline Yes & 279 & 52.1 \\
\hline No & 257 & 47.9 \\
\hline
\end{tabular}

ported to be boyfriend/husband 31 (16.2\%), family member/other relatives 12 (6.2\%), teacher 7 (3.7\%), students 65 (33.9\%), stranger 75 (39\%) and other 2 (1\%). In contrast to sexual harassment, the most frequent reported rape were intimate partners (boyfriend/husband) 20 (58.8\%), family members/relatives $4(11.8 \%)$, teacher 1 (2.9\%), student 2 (5.9\%), stranger 3 (8.8\%) and 4 (11.8\%) other.

\subsection{Factors Associated with Sexual Violence}

Factors associated with sexual violence, students with rural child hood residence were more than four times $(\mathrm{AOR}=4.51,95 \% \mathrm{CI}: 1.67-12.16)$ more likely to experience sexual violence than those with urban residence.
Students who reported to have a friend who drink alcohol (be male or female friends) were found to be at a higher risk of experiencing sexual violence than those who didn't have a fiend who drink alcohol $(\mathrm{AOR}=3.13$, 95\%CI: 1.09 - 8.97). Moreover, students who had no chance to discuss personal affairs with parents were about four times $(\mathrm{AOR}=4.36,95 \% \mathrm{CI}$ : $1.40-13.56)$ more likely to experience sexual violence than those who had the chance to discuss personal affairs especially on sexual issues with parents.

Age, religion, monthly family income and age of starting first sexual intercourse of the study participants didn't show any association with sexual violence. But all attributes of substance use (chat chewing, drinking of alcohol), educational year, marital status, current living condition, educational status of father, getting support from family, getting enough money, amount of money received, sexual activity, having more than one sexual partner, reasons for doing first sexual intercourse were found to be strong covariates of sexual violence in their life time on crude OR, none of them were associated after multivariate analysis (Table 5).

\section{DISCUSSION}

The prevalence of sexual violence was found to be $37.3 \%$ in their life time. The prevalence of any form of sexual violence that means sexual harassment and forced sexual intercourse (rape) was reported to be $35.8 \%$ and $6.3 \%$ in their life time respectively. Sexual violence among private college female students in Bahir Dar town was found to be a very common phenomenon.

A study conducted in Butajira among female high school and technical school students in 2006 revealed that the prevalence of sexual violence in their life time was reported $35 \%$ which is consistent with the corresponding value of our finding [9]. However, the finding of this study was lower as compared to the 2007 study conducted in Mekele among female higher learning institution students that revealed to be $45.4 \%$ in life time [6]. This could be due to the socio cultural and perception about sexual violence difference between the target populations. Our finding on sexual violence was higher as compared to national random surveys conducted in Barbados, Canada, Netherland, New Zealand, Norway and the United States revealed that $27 \%$ to $32 \%$ of women interviewed have been sexually abused during child hood $[10,11]$. This might be explained by the difference in study sitting and socio cultural contexts between the study populations.

A study conducted among high school students in Addis Ababa and Western show a indicated that life time rape was reported $5 \%$ which is consistent with the corresponding value of our finding [12]. But our finding on 
Table 5. Association of selected factors and sexual violence among private college students in Bahir Dar town, Amhara region, North West Ethiopia, April 2012.

\begin{tabular}{|c|c|c|c|c|}
\hline \multirow{2}{*}{ Variable categories } & \multicolumn{2}{|c|}{ Sexual violence } & \multicolumn{2}{|c|}{ OR (95\%CI for OR) } \\
\hline & yes & No & Crude OR & Adjusted OR \\
\hline \multicolumn{5}{|l|}{ Residence (child hood) } \\
\hline Urban & 101 & 227 & 1 & 1 \\
\hline Rural & 99 & 109 & $2.041(1.425,2.923)$ & $4.505(1.669,12.161)$ \\
\hline \multicolumn{5}{|l|}{ Educational year } \\
\hline First year & 85 & 86 & 1 & 1 \\
\hline Second year & 48 & 112 & $0.434(0.276,0.681)$ & $0.481(0.133,1.733)$ \\
\hline Third year & 67 & 138 & $0.491(0.323,0.746)$ & $0.701(0.214,2.294)$ \\
\hline \multicolumn{5}{|l|}{ Marital status } \\
\hline Married & 22 & 56 & 1 & 1 \\
\hline Have boyfriend & 63 & 78 & $2.056(1.135,3.726)$ & $2.156(0.674,6.895)$ \\
\hline No & 115 & 202 & $1.449(0.841,2.496)$ & $2.755(0.776,9.782)$ \\
\hline \multicolumn{5}{|l|}{ Getting enough money } \\
\hline Yes & 140 & 285 & 1 & 1 \\
\hline No & 60 & 51 & 2.395 (1.566, 3.662) & $0.833(0.191,3.634)$ \\
\hline \multicolumn{5}{|l|}{ Chewing chat } \\
\hline No & 159 & 307 & 1 & 1 \\
\hline Yes & 41 & 29 & $2.730(1.635,4.558)$ & $0.439(0.1397,1.389)$ \\
\hline \multicolumn{5}{|c|}{ Having a friend who drink alcohol } \\
\hline No & 52 & 80 & 1 & 1 \\
\hline Yes & 32 & 9 & $5.470(2.415,12.392)$ & $3.128(1.090,8.971)$ \\
\hline \multicolumn{5}{|c|}{ Have more than one sexual partner } \\
\hline No & 78 & 105 & 1 & 1 \\
\hline Yes & 51 & 12 & $5.721(2.859,11.449)$ & $2.640(0.945,7.377)$ \\
\hline \multicolumn{5}{|c|}{ Discus on sexual issues with family } \\
\hline Yes & 50 & 229 & 1 & 1 \\
\hline No & 150 & 107 & $6.421(4.330,9.520)$ & $4.355(1.399,13.555)$ \\
\hline
\end{tabular}

life time rape was lower as compared to a study conducted in Addis Ababa University the prevalence of life time rape among female students was $12.7 \%$ [13]. This could be due to socio cultural and study setting between the target populations.

Our finding of life time rape was lower than the finding from street adolescents aged 10 - 19 years in Addis Ababa that showed $15.6 \%$ in the period of three months prior to the survey [14]. Differences in study targets and study setting might be the explanation for the difference of findings.

In our study the prevalence of forced sex (rape) was $6.3 \%$. This finding disagrees with a study conducted in USA among adolescents $12 \%$ [15]. This might be due to the difference in socio cultural characteristics of the study targets and the contexts of forced sex (domestic forced sex). The finding of the current study is in accordance with a study done in Addis Ababa 5\%.

However, the magnitude of other forms of sexual violence especially sexual harassment was very low as compared to the finding of this same study 74.3\% [4]. This could be due to lack of awareness of the study women about sexual harassment as a sexual violence.

According to a cross sectional study among female students of Addis Ababa University, the prevalence of sexual harassment was reported to be $58 \%$ in life time [13]. Sexual harassment in the present study was about $35.8 \%$. This might be partly explained by self perception 
about sexual harassment. That means some people may not consider harassment as crime while others may consider it. This perception may vary from place to place, person to person, culture to culture.

Sexual violence was significantly associated with; rural child hood residence, history of alcohol consumption, having drunken peers (male or female friends). Among those who were sexually violated and not violated for factors having nearly living families with money support as needed was statically significance.

Our study has assessed some factors which are stated as contributing factors for sexual violence. Current sexual violence among female students was significantly associated with those not discussing personal issue including reproductive health with parents was statically significance. This could lead to lack of confidence and life skills useful in challenging or negotiate sexual relation.

This study signifies that the problem of sexual violence is sustained and aggravated because of stigma, social conformation and poor enforcement of the law especially in effecting to practice. It is clear from this study that sexual violence is a significant problem among female students in colleges. Females were shown to be victims of various forms of sexual violence which ranges from unwanted touch to forced sexual intercourse.

\section{CONCLUSIONS}

This study showed that the prevalence of sexual violence among private college female students is a serious problem. The findings of this study indicated that the prevalence of sexual harassment and forced sexual intercourse (rape) were common phenomena.

Factors which contribute to sexual violence include childhood residence, more than one sexual partner, drunken male or female friends and do not discuss personal issue with parents. In addition to these factors, lack of communications on sexual issues between spouses was shown to contribute to the problem.

\section{ACKNOWLEDGEMENTS}

We would like to thank Amhara Regional Health Bureau allowing us to conduct the study. We would also like to express our heartfelt gratitude to the following colleges: Alkan University College, Blue Nile College, High Land College and Tana Haike College. Our deepest gratitude goes to all the study participants, supervisors whose contribution was vital to the completion of the study.

\section{REFERENCES}

[1] WHO (1997) Violence against women: Aphordis health issue. World Health Organization, Geneva.

[2] Heise, L., Lori, et al. (1994) Violence against women: A neglected public health issue in less Developed countries. Social Science \& Medicine, 39, 1165-1179.

doi:10.1016/0277-9536(94)90349-2

[3] Gossaye, Y., Deyessa, N. and Berhane, Y. (2003) Butajira rural health program: Women's health and life events study in rural ethiopia. The Ethiopian Journal of Health Development, 17, 1-51.

[4] Mulugeta, E., Kassaye, M. and Berhane, Y. (1998) Prevalence and outcome of sexual violence among high school students in Addis Ababa and Western Showa. Ethiopian Medical Journal, 36, 167-173.

[5] Worku, A. and Addisie, M. (2002) Sexual violence among female high school students in Debark Northwest Ethiopia. East African Medical Journal, 79, 96-99. doi:10.4314/eamj.v79i2.8911

[6] Yaynshet, G., Yemane, B. and Nigussie, D. (2007) Prevalence and factors related to gender based violence among female students of higher learning institutions. Addis Ababa University, Addis Ababa.

[7] Miruts, G., Yemane, B. and Nigussie, D. (2006) Prevalence and factors related to sexual and physical violence among female high school and technical school studies Butajira, South Ethiopia. Addis Ababa University, Addis Ababa.

[8] Seblework, T., Ahmed, A. and Negussie, D. (2004) Assessments of sexual coercion among Addis Ababa University female students. Addis Ababa University, Addis Ababa.

[9] Goshu, M. (2006) Prevalence and Factors related to sexual and physical violence among female high school and technical school students of Butajira. Master Thesis, Addis Ababa University, Addis Ababa.

[10] Schei, B. and Barketeig, S. (1989) Gynecological impact of sexual and physical abuse by spouse: A study of random sample of Norwegian women. British Journal of Obstetetrics and Gynecology, 96, 379-1383.

[11] Council of Scientific Affairs (1992) American medical association: Violence against women. JAMA, 267, 31843189. doi:10.1001/jama.267.23.3184

[12] Worku, A. and Addisie, M. (2002) Sexual violence among female high school students in Debark Northwest Ethiopia. East African Medical Journal, 79, 96-99. doi:10.4314/eamj.v79i2.8911

[13] Tadesse, S. (2004) Assessments of sexual coercion among Addis Ababa University female students. Master Thesis, Addis Ababa University, Addis Ababa.

[14] Molla, M., Ismail, S., Kumie, A. and Kebede, F. (2000) Sexual violence among female street adolescents in Addis Ababa. The Ethiopian Journal of Health Development, 16, 119-127.

[15] Roberta, A., Gary, M.I. and Donald, P.O. (1980) Behavioral risk, emotional risk and child abuse among adolescents in a non clinical setting. Pediatrics, 186, 896-901. 